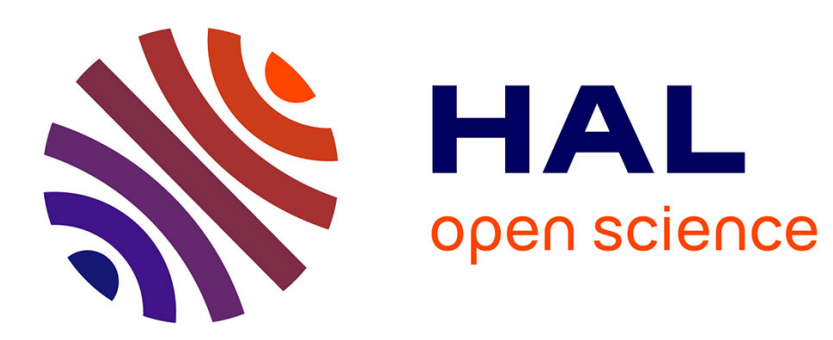

\title{
Assessment of the effect of 3D printed sand mold thickness on solidification process of AlSi13 casting alloy
}

\author{
Mariem Ben Saada, Mohamed El Mansouri
}

\section{To cite this version:}

Mariem Ben Saada, Mohamed El Mansouri. Assessment of the effect of 3D printed sand mold thickness on solidification process of AlSi13 casting alloy. International Journal of Advanced Manufacturing Technology, 2021, 114 (5-6), pp.1753-1766. 10.1007/s00170-021-06999-3 . hal-03220855

\section{HAL Id: hal-03220855 \\ https://hal.science/hal-03220855}

Submitted on 23 Jun 2021

HAL is a multi-disciplinary open access archive for the deposit and dissemination of scientific research documents, whether they are published or not. The documents may come from teaching and research institutions in France or abroad, or from public or private research centers.
L'archive ouverte pluridisciplinaire HAL, est destinée au dépôt et à la diffusion de documents scientifiques de niveau recherche, publiés ou non, émanant des établissements d'enseignement et de recherche français ou étrangers, des laboratoires publics ou privés. 


\title{
Assessment of the effect of 3D printed sand mold thickness on solidification process of AISi13 casting alloy
}

\author{
Mariem Ben Saada ${ }^{1} \cdot$ Mohamed El Mansori $^{1}$
}

\begin{abstract}
The present work addresses the printed sand mold thickness effect on the solidification process of a eutectic aluminum-silicon alloy (AlSi13). Several sand mold thicknesses (varying from 3 to $30 \mathrm{~mm}$ ) are numerically studied using Quikcast ${ }^{\circledR}$ software. The study shows that the solidification time decreases when the sand thickness of mold increases. It is accelerated by more than $40 \%$ when the sand mold thickness increases from 3 to $30 \mathrm{~mm}$. The numerical simulations are coupled with experiments. Indeed, the $3 \mathrm{D}$ sand printing process is used to fabricate molds presenting different thicknesses of $5 \mathrm{~mm}$ and $30 \mathrm{~mm}$, respectively. In addition, the same printing parameters are applied for producing all sand molds. The comparison between both numerical and experimental results shows the same tendency according to the sand mold thickness. The results indicate that increasing the sand mold thickness from 5 to $30 \mathrm{~mm}$ allows to accelerate the solidification by $17 \%$ and $18.6 \%$, respectively, in the numerical and experimental results. A finer microstructure is obtained when reducing the solidification time, which enhances the hardness of casting properties.
\end{abstract}

\section{Introduction}

The 3D sand printing (3DSP) process enables direct digital manufacturing of complex sand molds and cores for sand casting application from three-dimensional CAD design data [1]. It also allows replacement of permanent pattern molding for complex parts. Indeed, it permits to rapidly produce tooling (i.e., cores and molds) for complex metal castings that are otherwise difficult to manufacture using conventional sand casting. The 3DSP process provides unparalleled design freedom, which allows to increase the complexity of printed sand molds and cores neither in longer production time nor in higher cost [2].

Various studies had been conducted to understand the influence of printing parameters (such as binder content, powder recoating speed, catalyst content, layer thickness, aging process, and job box (i.e., building box) position of the printed specimen [3-7]) on the mold properties (density, permeability, strength [4, 8-10], etc. ...). Then, studies focused more on exploiting the unlimited potential of 3DSP process to redesign parts $[2,11,12]$, gating and feeding system [13, 14]. Recently, non-conventional mold designs were proposed to replace the traditional thick sand molds. These molds include two structures: lattice-shell and rib enforced shell. The shell forms the cavity for the casting and the surrounding ribs or lattices support and reinforces the shell [15-17]. The first advantage of using shell molds is to reduce the amount of molding sand. Consequently, the manufacturing cost decreases. Shangguan et al. $[15,16]$ showed that rib enforced shell sand mold allowed to save two-thirds of the mass of sand compared to traditional dense mold. The authors indicated also that, for aluminum-A 356 , the cooling time was reduced by over $25 \%$ when the temperature decreased from 700 to $200{ }^{\circ} \mathrm{C}$, knowing that the solidus temperature of the studied alloy was $556^{\circ} \mathrm{C}$. On the other side, Kang et al. [17] worked on the same type of molds as those presented in refs. $[15,16]$ and they showed that the solidification process was prolonged by around $15 \%$ when a cavity surrounding the riser was added (i.e., by decreasing the sand thickness around the riser). However, the authors were more interested in comparing the cooling time and the temperature evolution within the molds than in the cast parts. Indeed, 
the solidification process of casting alloys was not well studied as a function of shell thickness.

The effect of the shell thickness on the casting properties was more studied in the case of Zcast process, which uses a mixed powder of plaster and ceramic composite [18]. The authors in [19-21] showed that it was possible to reduce the shell thickness of Zcast molds from the recommended value of 12 $\mathrm{mm}$. Note that all these studies were investigated in thin cast parts. Singh et al. indicated that with a shell thickness of $5 \mathrm{~mm}$, the hardness of aluminum cast parts was improved by $3.8 \%$ $[19,20]$. Gill et al. showed that $3 \mathrm{~mm}$ and $6 \mathrm{~mm}$ were the optimum shell thickness to ensure better properties, respectively, for ZA-12 zinc and A356 aluminum alloys [21]. However, the decrease in shell thickness leads to an increase in the surface roughness [22]. Despite all these results, the literature on the topic of shell thickness provided scant information, in particular with other systems that used various sand-binder catalyst systems [5]. The resin (furan or phenol)-bonded sand (e.g., chromite, silica, zircon, or ceramic bead) molds may provide better properties due to the lower binder content compared to the Zcast molds. It is very important to quantify the effect of shell thickness - or in other words, the 3D printed (3DP) sand thickness - on the cast part properties before re-thinking complex molds design. Here, the question is raised about whether the 3DP sand thickness variation may improve the final mechanical properties of cast components.

The aim of this work is to study the influence of 3DP sand thickness on the solidification process of AlSil3 casting alloy and to provide quantified data, which will be very useful for mold redesign. In this respect, a numerical study using Quikcast ${ }^{\circledR}$ software on cylindrical sand molds is presented. Sand mold thickness varying from 3 to $30 \mathrm{~mm}$ is investigated. In order to confirm the numerical results, sand molds presenting, respectively, 5-mm and 30-mm thicknesses were printed. The 3DP process and parameters of these molds, as well as the properties of the melting alloy, are presented in detail in this paper.

\section{Description of the molds design using casting simulation}

\subsection{Part and mold design}

The alloy used in this study was the AlSi13. The cast parts and mold geometry are presented in Fig. 1. In order to highlight only the impact of the 3DP sand thickness, a simple cylindrical shape was opted for the geometry of both cast parts and molds, as shown in Fig. 1. The cast parts were composed of two parts, a cylindrical bar (i.e., casting cavity in Fig. 1) and a pouring cone to ensure perfect filling of the cavity without metal overflowing onto the mold. The cylindrical shape of the casting cavity allows to obtain a radial heat exchange and to avoid the effect of cast-part section variation on solidification rate $[23,24]$. It was also relatively high (i.e., $H=150 \mathrm{~mm}$, see Fig.1b) to avoid the effect of the pouring cone. In addition, using rotary-symmetrical molds (i.e., axisymmetric geometry) allows to ensure evenly cooling of cast parts, which means maximum warpage defect reduction [25].

The sand molds are composed of three parts as illustrated in Fig. 1: a casting cavity, a pouring cone, and a base for fixing the mold on the ground during casting. The molds were differed by the sand thickness around the part to be cast, which corresponds to the casting cavity in Fig. 1. In the present work, seven sand mold thicknesses were studied varying from 3 to $30 \mathrm{~mm}$. The choice of sand thickness values was based on casting simulation and the details of numerical parameters will be presented in the next section.

\subsection{Numerical simulation procedure}

The simulation of the filling and the solidification of the melt AlSi13 alloy were carried out using QuikCast ${ }^{\circledR}$, a finite volume casting simulation software. The simulation model used in this study assumed the conservation of mass, momentum, and energy during the solidification process in cast parts. The natural convection of the liquid alloy was controlled by the continuity (cf. Eq. (1): Continuity equation) and the NavierStokes (cf. Eq. (2): Momentum equation) and the heat transfer was controlled by the isotropic Fourier conduction law (cf. Eq. (3): Energy equation) [26, 27]:

$$
\begin{aligned}
& \nabla \cdot(\vec{V})=0 \\
& \frac{\partial \rho \Phi}{\partial \mathrm{t}}+\nabla \cdot(\rho \vec{V} \Phi)=\nabla \cdot(\mu \nabla \Phi)-\nabla P+\rho g \\
& \rho c_{\mathrm{p}} \frac{d T}{d t}=\nabla \cdot(\lambda \nabla T)+\dot{\mathrm{Q}}
\end{aligned}
$$

In the above equations, $\nabla$ is the vector operator divergence; $\vec{V}$ is the velocity vector, and $\Phi$ is a velocity component; $\rho$ is the density; $\mathrm{t}$ is time; $\mu$ is the dynamic viscosity; $\mathrm{P}$ is the pressure; $g$ is the gravity acceleration vector; $T$ is the temperature; $\lambda$ is the thermal conductivity of the fluid; $c_{\mathrm{p}}$ is the specific heat; and $\dot{Q}$ is an internal heat source and it is 0 for the mold and 1 for the cast part.

The conservation equations for mass, momentum, and energy were developed based on the following assumptions: (i) the liquid was Newtonian and incompressible and (ii) the convection was driven by thermal buoyancy.

The resin-bonded sand and the AlSi13 alloy properties, which already exist in the Quikcast ${ }^{\circledR}$ database, were used and are summarized in Table 1 . The sand density was $1590 \mathrm{~kg} \mathrm{~m}^{-3}$ and was supposed to be constant during the simulation. The heat transfer coefficient of the sand was $300 \mathrm{~W} \mathrm{~m}^{-2} \mathrm{~K}^{-1}[28]$ and the convective heat transfer coefficient between sand and air was $10 \mathrm{~W} \mathrm{~m}^{-2} \mathrm{~K}^{-1}$ [29]. The 
Fig. 1 Cast parts and sand molds geometry designed by catia V5 $(H$ is the height $/ \phi$ is the diameter): a 3-mm SM and b 30-mm SM
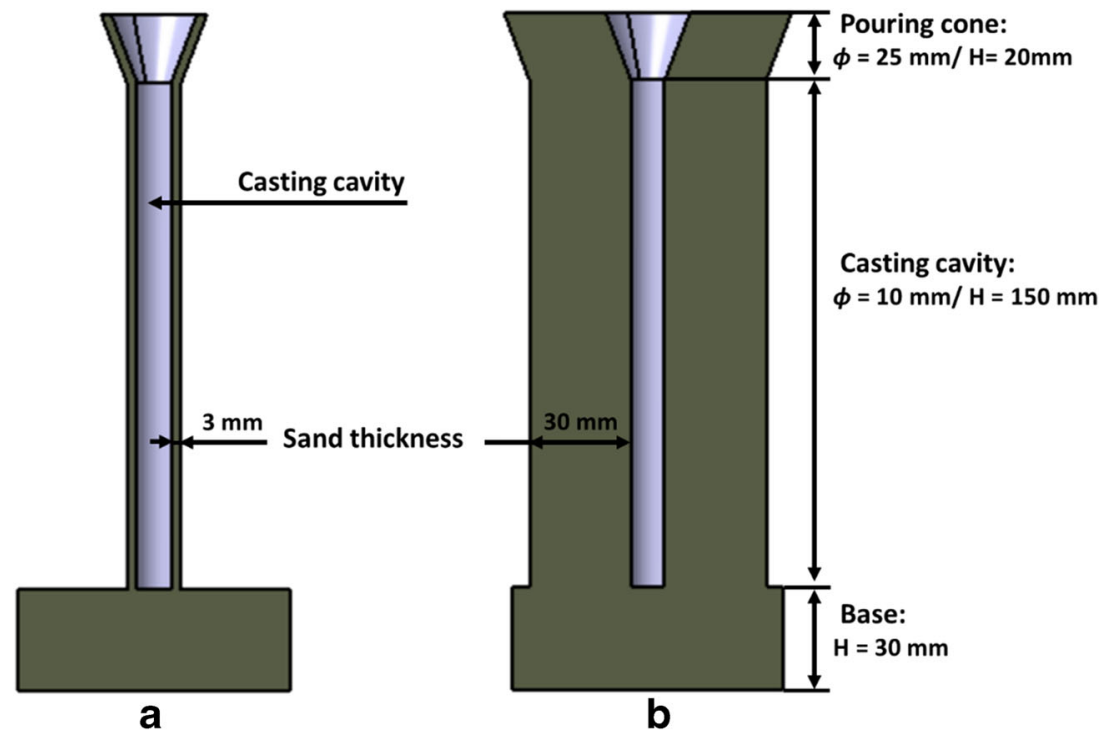

ambient temperature of the surrounding air was $20^{\circ} \mathrm{C}$. The pouring temperature of the melt AlSi13 alloy was $630^{\circ} \mathrm{C}$ and the liquidus and solidus temperatures were $572{ }^{\circ} \mathrm{C}$ and 570 ${ }^{\circ} \mathrm{C}$, respectively.

\subsection{Choice of sand mold thickness}

Seven sand mold thicknesses were numerically studied: 3 $\mathrm{mm}, 5 \mathrm{~mm}, 7 \mathrm{~mm}, 10 \mathrm{~mm}, 15 \mathrm{~mm}, 20 \mathrm{~mm}$, and $30 \mathrm{~mm}$.

Table 1 Thermal properties of the resin-bonded sand and the AlSi13 alloy in Quikcast database

\begin{tabular}{llll}
\hline $\begin{array}{l}\text { Temperature } \\
\left({ }^{\circ} \mathrm{C}\right)\end{array}$ & $\begin{array}{l}\text { Density } \\
\left(\mathrm{kg} \mathrm{m}^{-3}\right)\end{array}$ & $\begin{array}{l}\text { Specific heat } \\
\left(\mathrm{J} \mathrm{kg}^{-1} \mathrm{~K}^{-1}\right)\end{array}$ & $\begin{array}{l}\text { Conductivity } \\
\left(\mathrm{W} \mathrm{m}^{-1} \mathrm{~K}^{-1}\right)\end{array}$ \\
\hline $\begin{array}{l}\text { Resin-bonded sand properties } \\
20\end{array}$ & 670 & \\
100 & & 800 & 0.71 \\
200 & 920 & 0.68 \\
300 & & 883 & 0.64 \\
400 & 1006 & 0.60 \\
500 & & 1006 & 0.56 \\
600 & 1006 & 0.53 \\
700 & & 1006 & 0.50 \\
900 & & 1006 & 0.60 \\
AlSi13 alloy properties & & 0.73 \\
300 & 2600 & 1020 & \\
450 & 2578 & 1130 & 151.6 \\
550 & 2563 & 1200 & 147 \\
570 & 2560 & 1210 & 144 \\
572 & 2478 & 1210 & 143.5 \\
750 & 2431 & 1210 & 80 \\
\hline
\end{tabular}

Hereafter, the following designation is adopted to lighten the text: for example the mold having $3 \mathrm{~mm}$ of sand thickness is referred to by "3-mm SM" (i.e., 3-mm sand mold) and the corresponding cast part is referred to by " 3 mm-SM cast part."

The limits of the studied sand thickness interval that correspond to $3 \mathrm{~mm}$ and $30 \mathrm{~mm}$, respectively, were selected based on solidification simulation of the AlSi13 casting alloy. Figure 2 shows the numerical temperature mapping of AlSi13 alloy after solidification in the 3-mm $\mathrm{SM}$ and $30-\mathrm{mm}$ SM. In fact, the simulation was stopped when the temperature of all points in the cast parts reached a value of $560{ }^{\circ} \mathrm{C}$, slightly below the solidus temperature of the AlSi13 alloy (i.e., $570{ }^{\circ} \mathrm{C}$ ). The $3 \mathrm{~mm}$ sand thickness was the lowest value that can be printed to make a resisting mold during casting. This value depends simultaneously on the shape of the part to be cast and on the printing parameters, in particular the binder content and the recoater speed. The criterion for choosing $30 \mathrm{~mm}$ as a maximum thickness was linked to the fact that the temperature on the external walls of the mold, after total cast-part solidification, was the room temperature (i.e., $20^{\circ} \mathrm{C}$, see Fig. $2 \mathrm{~b}$ ), whereas, in the case of 3$\mathrm{mm} \mathrm{SM}$, the temperature reached the mold walls was about $300{ }^{\circ} \mathrm{C}$ (c.f. Fig. 2a).

The temperature evolution as a function of time was calculated with Quikcast ${ }^{\circledR}$, in the cast parts and in the molds, respectively, at nodes N1 and N2 (c.f. Fig. 2b). N1 is located in the middle of the cast parts, at a distance of $95 \mathrm{~mm}$ from the top surface of the casting cones. N2 is located at a distance of $2.5 \mathrm{~mm}$ from the edge of the cast parts and $105 \mathrm{~mm}$ from the top surface of molds, respectively. The node positions were chosen based on numerical results presented in Fig. 3. The figure shows longitudinal profiles of the temperature 
Fig. 2 Numerical temperature mapping of AlSi13 alloy after solidification as function of mold thickness: a 3-mm SM and b 30$\mathrm{mm} \mathrm{SM}$

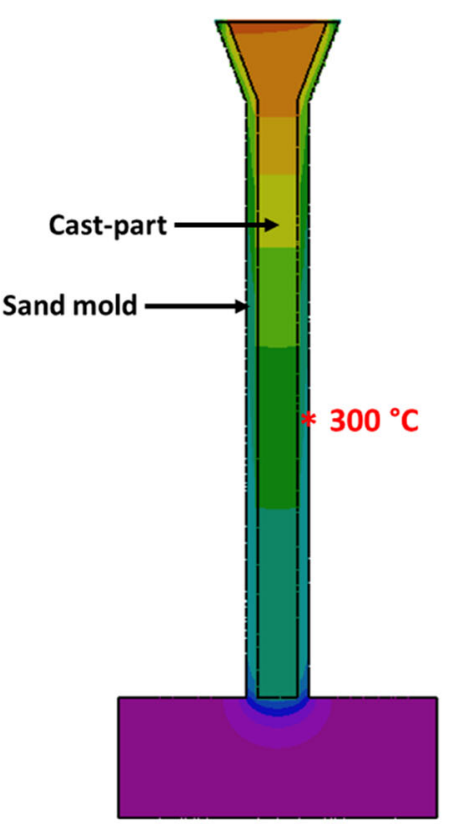

a

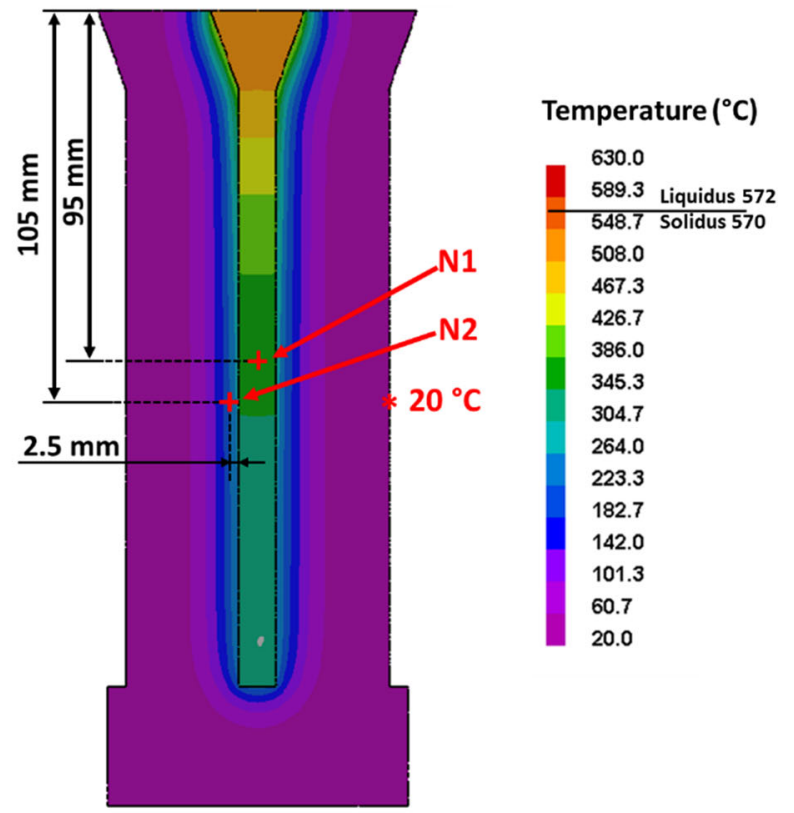

b throughout the 30-mm SM. These temperature profiles were obtained at different distances from the edge of the cast part. In order to avoid the impact of the pouring cone (i.e., the zone extended over $75 \mathrm{~mm}$ from the top surface of the casting cone) and the mold base (i.e., the zone extended over $60 \mathrm{~mm}$ from the base), the temperature was extracted in the middle of the interval of low-temperature variation, as illustrated in Fig. 3.

\section{Experimental procedure}

\subsection{D printing process}

The sand specimens and the sand molds were designed using Catia V5. Catia files were converted into .stl file format to be transferred to NetFabb software. The sand specimens were
Fig. 3 Temperature trends within the $30-\mathrm{mm}$ SM at different thickness locations from the edge of the cast part

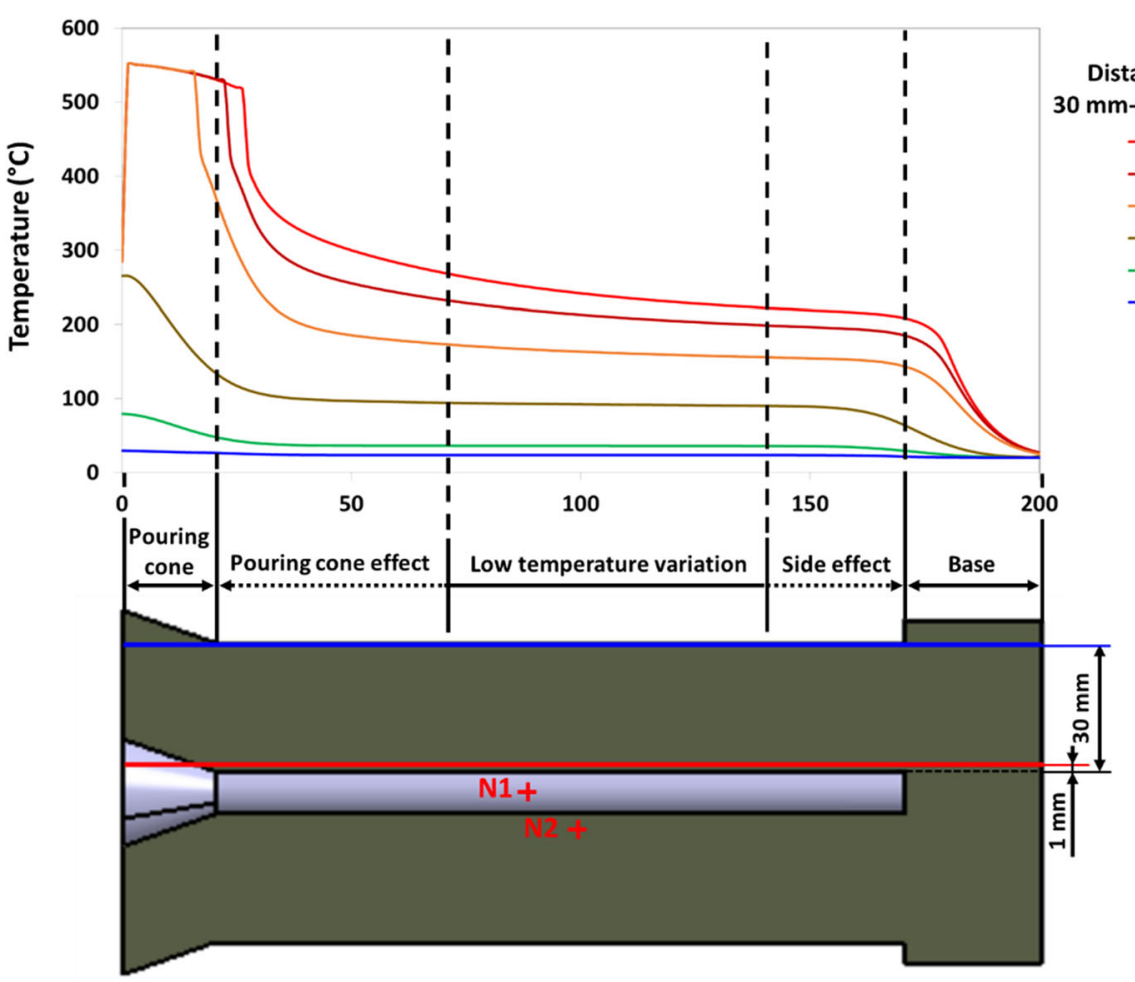


printed by means of the ExOne S-Print Furan machine equipped with an $800 \times 500 \times 400 \mathrm{~mm}^{3}$ job box [7]. The 3DSP process was performed in a room maintained at a temperature of $25^{\circ} \mathrm{C}$ and relative humidity of $40 \pm 10 \%$. The first step of the 3DSP process consisted of mixing the sulfonic acid catalyst $(0.18 \%$ of the weight of the sand) with $8 \mathrm{~kg}$ of quartz silica sand particles and storing it temporarily in the mixing chamber. The second step consisted of deposing a first sand layer of $1.4 \mathrm{~mm}$ in the job box in order to neglect sub-layer displacements and compressibility problems [30]. After that, a fine sand layer of $280 \mu \mathrm{m}$ was distributed on the job box by a recoater head. Then, the platform was lowered by one-layer thickness. The inkjet print head nozzles injected the furfuryl alcohol-based binder in the selected area to form one crosssectional layer of the part to be printed. A bonding reaction took place only in the region where the binder was sprayed; the other regions were covered by unbounded loose sand (i.e., binder-free sand). The process of sand layer deposition and the binder injection continued until the last slice of the sand specimen was printed and a final sand layer was deposed. The 3DP sand specimens were then cured for an hour at room temperature inside the job box to eliminate a portion of the binder. Finally, they were taken out of the job box, and depowdered to remove the unbounded loose sand.

\subsection{D printing parameters}

The aim of this study is to print sand molds that should be rigid enough to resist during casting and sufficiently permeable to facilitate the gases released. For these reasons and based on the laboratory's knowledge of the 3DSP process [5-7, 31-34], the printing parameters listed in Table 2 are chosen. A special attention was given to the $\mathrm{X}$ resolution $\left(\mathrm{X}_{\mathrm{r}}\right.$, i.e., binder content) and the recoater speed $\left(\mathrm{R}_{\mathrm{s}}\right)$. The $X$ resolution has a direct influence on the mechanical strength of the printed sand specimens [6, 32-35]. The decrease of the binder content leads to a considerable decrease in strength. Conversely, the higher binder content increases the strength of the printed sand specimens but it generates more gas during casting, which can cause defects in the casting parts $[6,8]$. Regarding the recoating speed effect, it has an influence not only on the mechanical strength but also on the specimen's permeability $[5,6,33,36]$. Indeed, the high speed gives rise to non-uniform compaction of the sand layer and therefore lower packing density due to high porosity. On the other side, low recoating speed leads to high sand density, inducing higher flexural strength. In relation with the above, the applied binder content and recoater speed were respectively $1.49 \pm 0.07 \%$ (of the sand weight) and $208 \mathrm{~mm} \mathrm{~s}^{-1}$. The details of the printing parameters of the selected recipe are presented in Table 2 .

\subsection{DP sand characterization}

Rectangular bar (length $=172 \mathrm{~mm}$, width $=22.4 \mathrm{~mm}$ ) and cylindrical shaped specimens $($ diameter $=50 \mathrm{~mm}$, height $=$ $50 \mathrm{~mm}$ ) were printed to perform 3-point bending strength and permeability measurements, respectively. The sand specimen characterization techniques used in this article have been described and detailed in [6, 7, 33]. Only a brief description was reviewed hereafter.

Three-point bending tests were performed on the printed sand bars using a universal strength test machine (SimpsonElectrical PFG type) to determine their bending strength. The bars were placed on two supporting pins spaced apart by 150 $\mathrm{mm}$. A third pin at the mid-length of each sand bar applied a load at a rate of $0.1 \mathrm{MPa} \mathrm{s}^{-1}$ until the specimen broke. This bending test was done using an electric motor with a maximum load capacity of $12.8 \mathrm{MPa}$. The reading uncertainty on the pressure gauge was $\pm 0.05 \mathrm{MPa}$.

Permeability measurement was performed on the cylindrical sand specimens using a digital permeability meter. This machine is characterized by a measuring range from 0 to 1000 $\mathrm{GP} \pm 1 \mathrm{GP}$. The orifice standard method was applied as per the recommendations of the American Foundry Society [7].

The sand characterization shows that the 3DP specimens have an average density of $1300 \mathrm{~kg} \mathrm{~m}^{-3}$, which exhibits $51 \%$ of porosity. They present also a 3-point bending strength of $2.2 \pm 0.5 \mathrm{MPa}$ and permeability of $95 \pm 16 \mathrm{GP}$. All the results are in agreement with the preceding literature $[6,7,33]$. They confirm that the selected recipe, detailed in Section 3.2, allows to obtain a good compromise in the mechanical properties of the molds over a wide range of sand thickness. However, the associated strength is not enough to print the 3-mm SM. Hence, the minimal sand thickness used to print molds was
Table 2 3DSP process parameters

\begin{tabular}{ll}
\hline Average grain size & $140 \mu \mathrm{m}$ \\
\hline Recoating speed $\left(R_{\mathrm{s}}\right)$ & $\begin{array}{c}208 \mathrm{~mm} \mathrm{~s}^{-1} \text { which corresponds to } 16 \% \text { of the } \\
\text { maximum achievable speed by the recoater-Sprint ExOne }\end{array}$ \\
X resolution $\left(X_{\mathrm{r}}\right)$ & $120 \mu \mathrm{m}$ \\
$Z$ resolution: sand layer thickness & $280 \mu \mathrm{m}$ \\
Print head voltage & $85 \mathrm{~V}$
\end{tabular}


$5 \mathrm{~mm}$. 30-mm SM was also printed, which corresponds to the upper limit of the studied sand thickness interval.

\subsection{Melting alloy and cast-part characterization}

An aluminum-silicon alloy AlSi13 (EN AC-4400: US designations of the Aluminum Association) was used in this study. It was slightly hypereutectic as the silicon was about $12.8 \mathrm{wt} \%$ (i.e., the eutectic point of the Al-Si is $12.6 \mathrm{wt} \%$ [37]). The exact chemical composition was obtained by SPECTROMAXx optical emission spectroscopy and is summarized in Table 3. The AlSi13 alloy was chosen because it is commercially very popular and widely used in foundry since it exhibits excellent fluidity, cast ability, corrosion resistance, and crack resistance [38-40]. The AlSi13 alloy ingots were melted at $700{ }^{\circ} \mathrm{C}$, in $12 \mathrm{~kW}$ resistance furnace (type: NPG.45, voltage: $380 \mathrm{~V}$, current: $19 \mathrm{~A}$ ) in a carbide crucible. The parts were cast by gravity at a pouring temperature around $630{ }^{\circ} \mathrm{C}$.

Three thermocouples were placed for each experimental test in order to measure the temperature evolution within the cast part and the sand mold: one thermocouple was placed at node N1 (i.e., in the middle of the cast part) and the two others were placed at node $\mathrm{N} 2$ (i.e., at $2.5 \mathrm{~mm} \pm 0.5 \mathrm{~mm}$ from the cast-part edge). The thermocouple position was determined based on the numerical study as explained above in Section 2.3 (cf. Fig. 2b).

The number of the thermocouples was reduced to three in order to minimize the heat transfer disturbance. The data were recorded every $20 \mathrm{~ms}$, during casting, solidification, and cooling to room temperature, and were stored in a multichannel recorder (Hioki LR8431-20 recorder). The analysis process included plotting the cooling curves and identifying the solidification parameters such as solidification rate, undercooling, and eutectics plateau.

For microstructural analyses, radial sections were performed at the middle of the cast parts. The obtained samples were polished mechanically in three main steps: a first grinding with silicon carbide disks (grit from 500 to 4000), and diamond polishing with $3 \mu \mathrm{m}$ and $1 \mu \mathrm{m}$ diamond suspensions, respectively. Polished samples were observed by an Olympus optical microscope in order to highlight the impact of the 3DP sand thickness on the cast-part microstructure.

A QNESS hardness tester was used for performing Vickers microhardness. The tests were conducted by applying $5 \mathrm{~kg}$ for $10 \mathrm{~s}$ with square-based pyramid indenter on the surface of the

Table 3 Chemical compositions of the AlSi13 alloy in wt $\%$

\begin{tabular}{llllllll}
\hline $\mathrm{Si}$ & $\mathrm{Cu}$ & $\mathrm{Mg}$ & $\mathrm{Fe}$ & $\mathrm{Zn}$ & $\mathrm{Mn}$ & $\mathrm{Sr}$ & $\mathrm{Al}$ \\
\hline 12.77 & 0.06 & 0.01 & 0.49 & 0.01 & 0.13 & $<0.0001$ & 86.45 \\
\hline
\end{tabular}

polished cast samples. For each sample, about 35 measurements were performed.

\section{Results and discussion}

\subsection{Influence of the 3DP sand mold thickness on the solidification process}

Figure 4 shows the numerical cooling curves of the AlSi13 casting alloy in the sand molds presenting different thicknesses varying from $3 \mathrm{~mm}$ to $30 \mathrm{~mm}$. The curves were obtained with Quikcast $\AA^{\circledR}$ at the same position in the cast parts. Such a temperature-time curve gives qualitative information about the alloy solidification process and can be used to predict the microstructure of the cast parts. The cooling curves are made up of three domains that correspond to the alloy phase change as illustrated in Fig. 4, in the case of the 30-mm-SM cast part. The first domain $[\mathrm{p}$, Eut,N] corresponds to the temperature interval between the pouring temperature $\left({ }_{p}\right)$ and the eutectic nucleation temperature ( Eut,N). In this interval, the alloy is in the liquid state. The slope of this curve allows to obtain the "solidification rate" of the cast part. The second domain $[$ Eut,N, s] corresponds to the solidification interval of the casting alloy. This domain starts with an undercooling process, which relates to the nucleation of the first eutectic germ and therefore to the beginning of alloy solidification. After nucleation, the eutectic germs grow and this process is illustrated by a plateau in which the temperature is almost constant around $570{ }^{\circ} \mathrm{C}$. In the case of eutectic alloys, the plateau duration $\left(\Delta t_{\text {Eut,G}}\right)$ is a good indication of the solidification duration [38]. The third and last domain $\left[\mathrm{s}, 20^{\circ} \mathrm{C}\right]$ corresponds to the cooling of solid alloy until the ambient temperature.

The comparison between the results in Fig. 4 shows that the slopes of the cooling curves are similar, about $20{ }^{\circ} \mathrm{C} \mathrm{s}^{-1}$, regardless of the sand mold thickness. Added to that, the duration of this first domain $[\mathrm{p}$, Eut, $\mathrm{N}]$ is about $2.5 \mathrm{~s}$ and is almost the same for all the cast parts. This interval actually corresponded to the time for the heat to reach the external walls of 3-mm SM as illustrated in Fig. 5. This figure presents the different stages of heat transfer, within the thinnest sand molds used in this study (i.e., presenting a thickness of $3 \mathrm{~mm}$, $5 \mathrm{~mm}$, and $7 \mathrm{~mm}$, respectively) and in their corresponding cast parts, during the first seconds after pouring. In the case of 3$\mathrm{mm} \mathrm{SM}$, the temperature at the external mold walls increased and reached about $40{ }^{\circ} \mathrm{C}$ in $2.5 \mathrm{~s}$, whereas in the $5-\mathrm{mm} \mathrm{SM}$, the temperature increased only slightly (about $21^{\circ} \mathrm{C}$, c.f. Fig. 5). From $7 \mathrm{~mm}$ of sand thickness, the temperature at the external mold surface did not change. According to simulation, the heat reached the $3-\mathrm{mm}$ SM edge after about $2.5 \mathrm{~s}$, which was not the case for the other molds, hence, the change of the alloy behavior (see Fig. 4). 
Fig. 4 Numerical cooling curves of the sand cast AlSil3 alloy

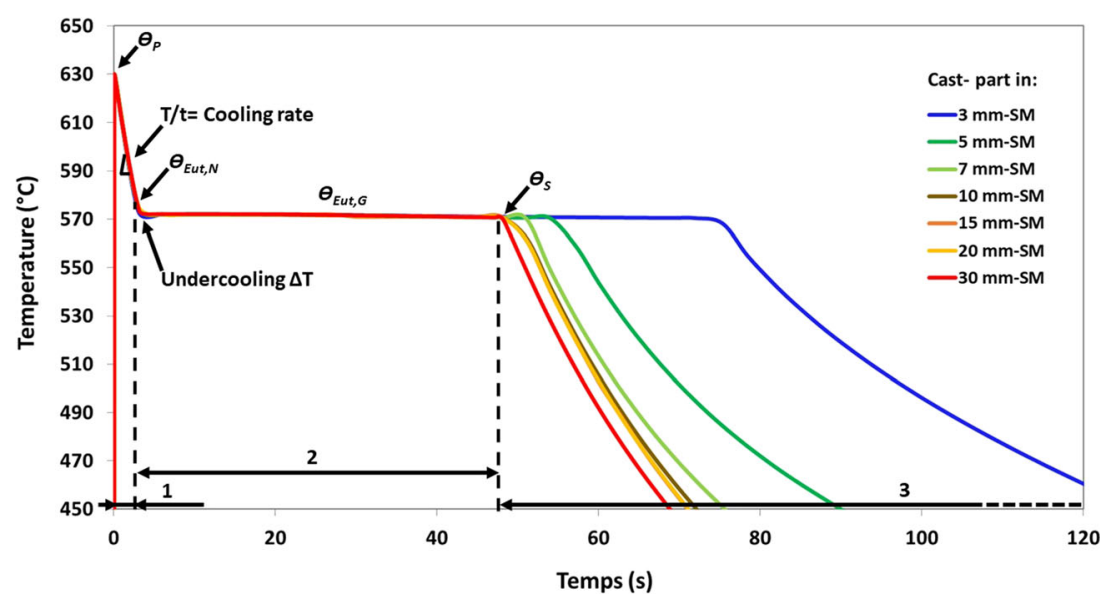

To better quantify the influence of the sand thickness on the microstructure of cast parts, it is necessary to focus on the second domain [ Eut,N, s] for eutectic alloys. Since the solidus temperature $\mathrm{s}$ is reached, the mold thickness variation has no impact on the cast-part properties [38]. In this domain, the results show that the $\Delta t_{\mathrm{Eut}, \mathrm{G}}$ is significantly affected by the sand mold thickness. Indeed, $\Delta t_{\text {Eut, G }}$ decreased when the mold thickness increased as illustrated in Fig. 6. For sand thickness varying from 10 to $20 \mathrm{~mm}, \Delta t_{\text {Eut,G }}$ was $46 \mathrm{~s}$ for all cast parts. Then, it slightly decreased when the sand thickness increases to $30 \mathrm{~mm}$ (cf. Fig. 6). The longest eutectic plateau was $73 \mathrm{~s}$, obtained with 3-mm-SM cast part (i.e., in the thinnest mold) and the shortest one was $44 \mathrm{~s}$, obtained with 30-mm-SM cast part (i.e., in the thickest mold). Thus, the solidification was accelerated over $40 \%$.

Figure 7 groups the temperature evolution within the sand molds. The curves were recorded at the same position, which corresponds to a distance of $2.5 \mathrm{~mm}$ from the edge of the cast part. Table 4 summarizes the maximum temperature reached in the molds and the corresponding necessary time to reach them. The results show that for all molds, the temperature increased quickly to reach a certain maximum value and then it decreased. Nevertheless, many differences were revealed according to the mold thickness (c.f. Fig. 7 and Table 4). The maximum temperature value decreased with increasing the sand mold thickness. The highest values of temperature were reached in the case of the thinner molds: they were around $412{ }^{\circ} \mathrm{C}$ and $335{ }^{\circ} \mathrm{C}$, reached within $88.4 \mathrm{~s}$ and 87.1 $\mathrm{s}$, respectively, in the 3-mm SM and the 5-mm SM. Besides, in the case of 30-mm SM, the maximum temperature was about $232{ }^{\circ} \mathrm{C}$, reached in only $66 \mathrm{~s}$. It is roughly 1.8 and 1.5 time lower compared to 3-mm SM and the 5-mm SM, respectively. The maximum temperature reached in the 15-mm SM, 20-mm $\mathrm{SM}$, and 30-mm SM was almost the same. After cast-part solidification, the temperature was still higher in the thinner molds until it reached around $150{ }^{\circ} \mathrm{C}$ (c.f. Fig. 7). Then, the temperature decreased quickly until the ambient temperature with high cooling rate compared to the thick molds.

All the revealed differences are related to the sand mold thickness. Indeed, from a thickness of $7 \mathrm{~mm}$, the heat does not arrive to the external mold walls before the part solidification end. In this case, the heat extraction from alloy flux is totally
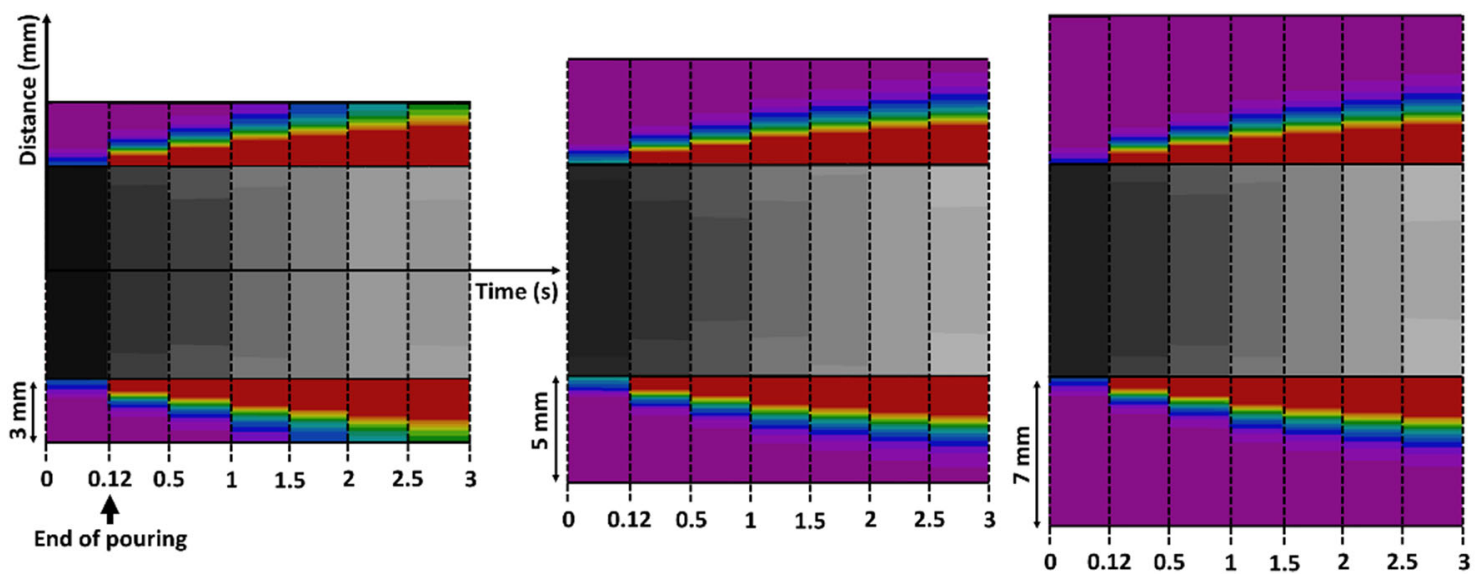

Temperature in: Cast-part Sand mold

\begin{tabular}{|l|l|}
630.0 & 70.0 \\
625.7 & 66.7 \\
621.3 & 63.3 \\
617.0 & 60.0 \\
612.7 & 56.7 \\
608.3 & 53.3 \\
604.0 & 50.0 \\
599.7 & 46.7 \\
595.3 & 43.3 \\
591.0 & 40.0 \\
586.7 & 36.7 \\
582.3 & 33.3 \\
578.0 & 30.0 \\
573.7 & 26.7 \\
569.3 & 23.3 \\
565.0 & 20.0 \\
\hline
\end{tabular}

Fig. 5 Temperature evolution during the first $3 \mathrm{~s}$ after cast pouring in the 3-mm SM, 5-mm SM, and 7-mm SM, respectively 
Fig. 6 Effect of the sand mold thickness on the eutectic plateau duration $\left(\Delta t_{\mathrm{Eut}, \mathrm{G}}\right)$ of cast parts

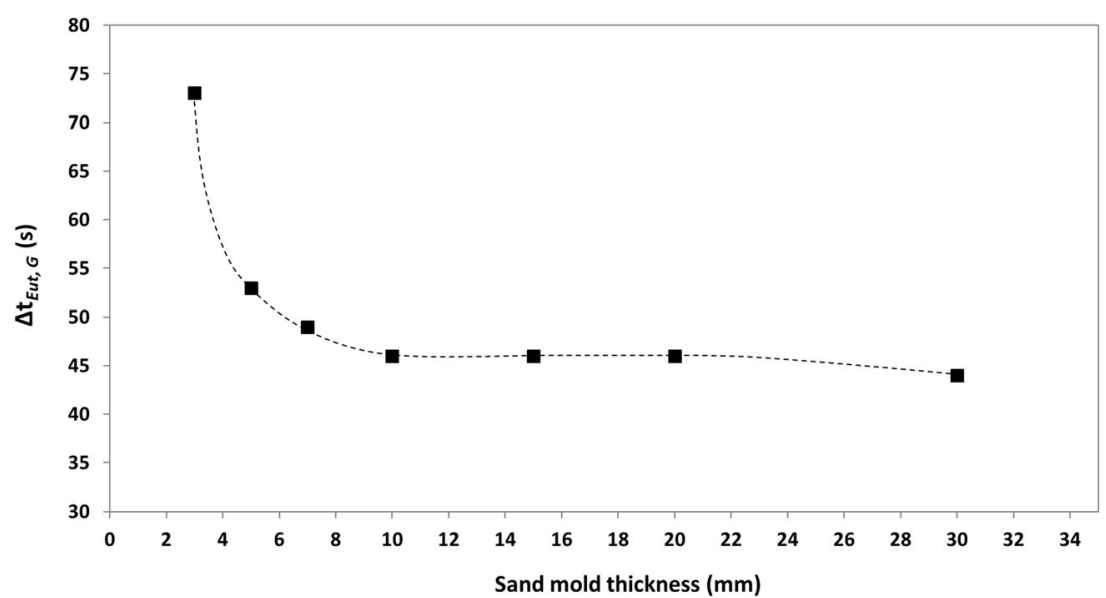

determined by heat conduction in the mold. The result is expected and it is in good agreement with literature [41], supposing that heat transfer is unidirectional. Thus, the heat released during solidification is transferred within the mold, with a high heat transfer coefficient (supposed to be $300 \mathrm{~W}$ $\mathrm{m}^{-2} \mathrm{~K}^{-1}$ in Quikcast simulation [28]). On the opposite, and for the sand mold thickness less than $5 \mathrm{~mm}$, the heat arrives to the mold walls in few seconds before the solidification beginning. Once the heat reaches the mold walls, it is transferred to the air essentially by natural convection. Natural convection was caused by buoyancy forces due to density differences produced by temperature variations in the air. The heat transfer coefficient between the sand and the air was about $10 \mathrm{~W} \mathrm{~m}^{-2}$ $\mathrm{K}^{-1}$ [29], which is 30 times less than the heat coefficient transfer between the alloy and the sand mold. This creates a thermal resistance at the mold walls and consequently the heat transfer within the mold is slowed down.

The numerical results show that increasing the 3DP sand mold thickness allows to accelerate the solidification of the casting. Thus, the mechanical properties of cast parts can be improved. In the range of the studied thicknesses and according to the cast-part shape, the $30-\mathrm{mm} \mathrm{SM}$ allows to obtain the lowest solidification time (i.e., the smallest $\Delta t_{\mathrm{Eut}, \mathrm{G}}$; ; that means the fastest solidification. Nevertheless, reducing the 3DP sand mold thickness allows to accelerate the cooling of the molds, after part solidification, and also to decrease the amount of printed sand. Thus, the cost of manufacturing is lower. A compromise between reducing the solidification time and the manufacturing cost of 3DP sand molds can be achieved by using only $15 \mathrm{~mm}$ of sand thickness, since the results obtained with $15-\mathrm{mm}$ SM were very close to those of $30 \mathrm{~m} \mathrm{SM}$ in terms of solidification time. Indeed, the solidification of the $30-\mathrm{mm}-\mathrm{SM}$ cast part was accelerated by around $4.5 \%$ compared to $15-\mathrm{mm}-\mathrm{SM}$ cast part. Besides, the amount of required sand was reduced by around 2 times.

\subsection{Experimental validation}

In order to confirm and validate the numerical study of the influence of 3DP sand thickness, molds presenting, respectively, $5 \mathrm{~mm}$ and $30 \mathrm{~mm}$ of sand thickness were printed. It
Fig. 7 Numerical simulation of the temperature evolution within the sand molds

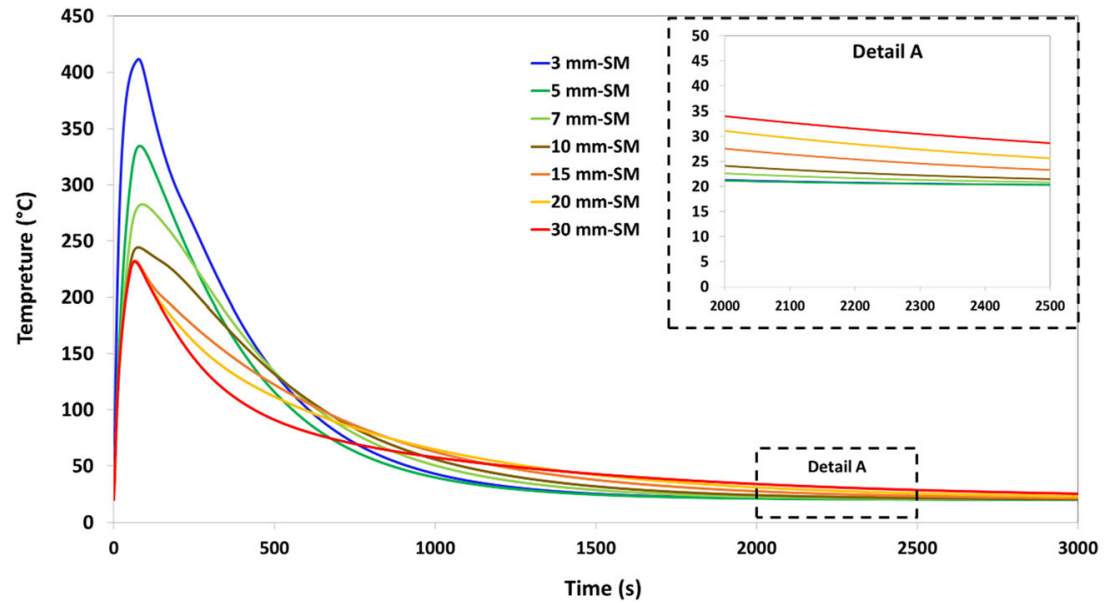


Table 4 Maximum temperature reached in the molds and the corresponding time

\begin{tabular}{lllllll}
\hline Sand thickness $(\mathrm{mm})$ & 3 & 5 & 7 & 10 & 15 & 20 \\
\hline Temperature $\left({ }^{\circ} \mathrm{C}\right)$ & 412 & 335 & 283 & 245 & 233 & 233 \\
Time (s) & 88.4 & 87.1 & 84.3 & 78.2 & 67 & 66.2 \\
\hline
\end{tabular}

was not possible to print 3-mm SM for reasons related to the strength of the selected sand recipe as detailed in Section 3. The numerical results corresponding to these molds were already presented in the previous section and they are superposed and compared with the experimental results in this section. The comparison between the experimental and numerical results was qualitative since the thermal properties of the sand and the alloy were not experimentally characterized.

When comparing the cooling curves presented in Fig. 8, one can conclude that both numerical and experimental results present the same tendency. The duration of the first domain [ $\mathrm{p}$, Eut,N] is close; $2.5 \mathrm{~s}$ in the numerical cooling curves and about $2 \mathrm{~s}$ and $2.5 \mathrm{~s}$, respectively, in 5-mm-SM and 30-mm-SM cast parts. The difference in the experimental results can be linked to the sensitivity of thermocouples. According to simulation, the slope of the cooling curves was the same (about 20 ${ }^{\circ} \mathrm{C} \mathrm{s}^{-1}$ ) regardless of the mold thickness, whereas, it was not the case in the experimental results. In fact, the experimental solidification rates of 5-mm-SM and 30-mm-SM cast parts were $27{ }^{\circ} \mathrm{C} \mathrm{s}^{-1}$ and $21{ }^{\circ} \mathrm{C} \mathrm{s}^{-1}$, respectively (c.f. detail b in Fig. 8). The difference cannot be related to the intrinsic properties of the sand since the same recipe was applied for all the printed molds (i.e., same printing parameters). It can be related to the pouring temperature since the $30-\mathrm{mm}-\mathrm{SM}$ cast part was poured at a higher temperature $\left(622{ }^{\circ} \mathrm{C}\right.$ vs $600{ }^{\circ} \mathrm{C}$ in the case of 5-mm-SM cast part). The solidification rate as a thermodynamic parameter is significantly affected by the pouring temperature, and it would decrease with increasing the pouring temperature [42]. The solidification rate in 30-mm-SM cast part was higher in the beginning until the temperature reached about $600{ }^{\circ} \mathrm{C}$. At this time, the sand had already heated up and consequently, the solidification rate in $30-\mathrm{mm}-\mathrm{SM}$ cast part decreased. Thus, the average solidification rate was lower in 30-mm-SM cast part.

In the solidification domain [ Eut,N, s], the curve of the 30mm-SM cast part presented low undercooling, which lead to a smaller $\Delta \mathrm{T}$ parameter $\left(\Delta T=7^{\circ} \mathrm{C}\right.$ and $12{ }^{\circ} \mathrm{C}$ respectively for 30-mm-SM and 5-mm-SM cast parts, cf. Fig. 8). A low undercooling means a larger interlamellar spacing [43, 44]. Yet, it is well known that, in the eutectic microstructure, the interlamellar spacing is the main parameter that controls its mechanical properties [44, 45]. Indeed, the interlamellar space is strongly dependent on the cooling conditions during solidification [46].

The 30-mm-SM cast part presented the shortest eutectic plateau $\Delta t_{\text {Eut,G }}$. The experimental solidification times of 5 $\mathrm{mm}-\mathrm{SM}$ and 30-mm-SM cast parts were, respectively, $43 \mathrm{~s}$ and $35 \mathrm{~s}$. The result is consistent with the simulation since the $\Delta t_{\text {Eut, G }}$ was $53 \mathrm{~s}$ and $44 \mathrm{~s}$, respectively, in 5-mm-SM and 30$\mathrm{mm}-\mathrm{SM}$ cast parts. Therefore, increasing the 3DP sand mold thickness from 5 to $30 \mathrm{~mm}$ leads to reducing the eutectic plateau by $8 \mathrm{~s}$ and $9 \mathrm{~s}$ according to the experimental and numerical results. Thus, the solidification is accelerated by around $17 \%$ and $18.6 \%$, respectively. Both numerical and experimental results evidence that the solidification is faster in a thick mold. The faster the solidification, the finer the
Fig. 8 Numerical and experimental cooling curves of the cast AlSi13 alloy in 5-mm SM and $30-\mathrm{mm} \mathrm{SM}$

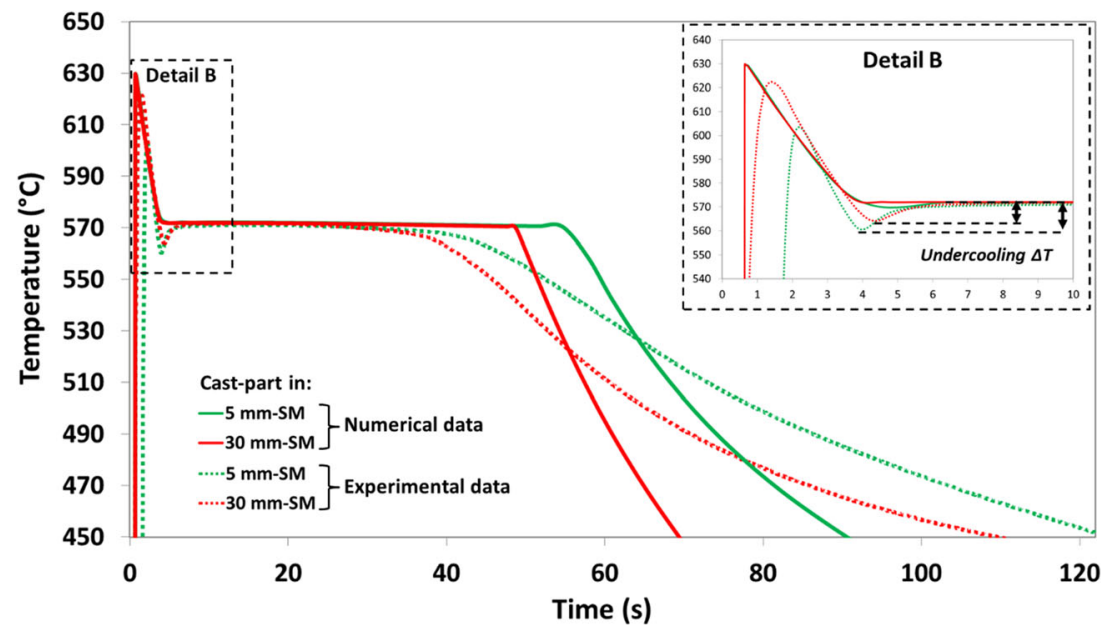


microstructure and the greater the mechanical properties of the cast parts. For Al-Si eutectic alloy, the solidification rate has a major influence on the size, morphology, and distribution of the eutectic silicon particles [43, 44]. Increasing the solidification rate can refine the eutectic silicon particles and changes their morphology $[47,48]$. Indeed, the eutectic structure has significant effects on the mechanical properties of Al-Si alloys $[43,44]$.

Figure 9 groups the experimental and the numerical temperature evolutions in both molds. The comparison between the curves shows the same tendency. The maximum temperature reached was always higher in the thin mold (i.e., $5-\mathrm{mm}$ $\mathrm{SM}$ ) and it was reached at longer time compared to $30-\mathrm{mm}$ SM. It was about $335^{\circ} \mathrm{C}$ and $340{ }^{\circ} \mathrm{C}$ for 5 -mm SM and about $232{ }^{\circ} \mathrm{C}$ and $265^{\circ} \mathrm{C}$ for $30-\mathrm{mm} \mathrm{SM}$, respectively, in the numerical and experimental results. After solidification (i.e., after about $12 \mathrm{~min}$ ), the temperature was higher in $30-\mathrm{mm} \mathrm{SM}$ until it reached around $140{ }^{\circ} \mathrm{C}\left(70{ }^{\circ} \mathrm{C}\right.$ in the numerical results, see Fig. 7). Then, the temperature decreased with high cooling rate compared to 5-mm-SM mold. For instance, $22 \mathrm{~min}$ and $45 \mathrm{~min}$ were respectively necessary for $5-\mathrm{mm}-\mathrm{SM}$ and 30 $\mathrm{mm}$-SM sand molds to reach a temperature of $50{ }^{\circ} \mathrm{C}$. Thus, the $5 \mathrm{~mm}$ sand thickness saved around $51 \%$ of the cooling time. It saved around $36 \%$ according to the simulation. The examinations of all cast parts, after cooling to ambient temperature, showed that the warpage defect did not occur, which evidences that the cooling was uniform in the studied case.

Certainly, there is a gap between the experimental and numerical results concerning the temperature profiles within the molds. The deviation between the results could be related to the sensitivity of thermocouples and their locations in the mold. Added to that, the thermocouples were manually placed in each mold. In spite of the major care dedicated to the instrumentation, the thermocouples could be positioned in the molds with a shift estimated to $\pm 0.5 \mathrm{~mm}$ relative to the desired location (c.f. at "N2" position, see Fig. 2b). In order to analyze the impact of the thermocouple location on the temperature evolution within the mold, a numerical study has been investigated. Figure 10 groups the temperature curves recorded in three positions within the $30-\mathrm{mm} \mathrm{SM}$, at a distance of $2 \mathrm{~mm}$ (position 1), $2.5 \mathrm{~mm}$ ("N2" position) and $3 \mathrm{~mm}$ (position 2), respectively, from the edge of the cast part. The results show that the variation in the location of the thermocouples leads to a temperature deviation and can reach a maximum of $50{ }^{\circ} \mathrm{C}$ when the position shifted by $1 \mathrm{~mm}$ (c.f. the maximum shift). The deviation was only observed in the first part of the curves, for the first $5 \mathrm{~min}$ (c.f. Fig. 10). Therefore, the difference between the numerical and experimental results, as seen in Fig. 7, cannot be attributed only to the location of thermocouples within the molds. As explained above, the thermal properties of the sand recipe were not experimentally characterized and the standard database of Quikcast software was used for the numerical simulations. All these factors make it possible to induce deviation in the temperature curves.

Despite all the differences between both numerical and experimental results, they are still showing similar tendency. The evidence that the sand thickness has an impact on the solidification process and that the solidification is faster in a thick mold. Hence, it affects the microstructural properties of the cast part as shown in Fig. 11.

Figure 11 presents the micrographs of samples prepared from as-cast AlSi13 alloy in the 5-mm SM and 30-mm SM, respectively. These micrographs reveal a eutectic structure of $\mathrm{Al}-\mathrm{Si}$ alloy. Its principal structural component is coarse lamellas of $\alpha$ (light) and $\mathrm{Si}$ (dark) and small amounts of primary silicon crystals ( $\mathrm{Si}$ ) phase, characteristic of the siliconcontaining alloys. These primary Si particles provide improved wear resistance [40]. The comparison between the microstructures shows that the distribution of the lamellas $(\alpha / \mathrm{Si})$ was irregular in both samples. However, the interlamellar spacing was very large in the 5-mm-SM cast sample. In contrast, 30-mm-SM cast sample was characterized by more numerous and closer lamellas (finer structure). The interlamellar space was very small in this sample. The revealed
Fig. 9 Numerical and experimental curves of the temperature evolution in 5-mm SM and 30-mm SM

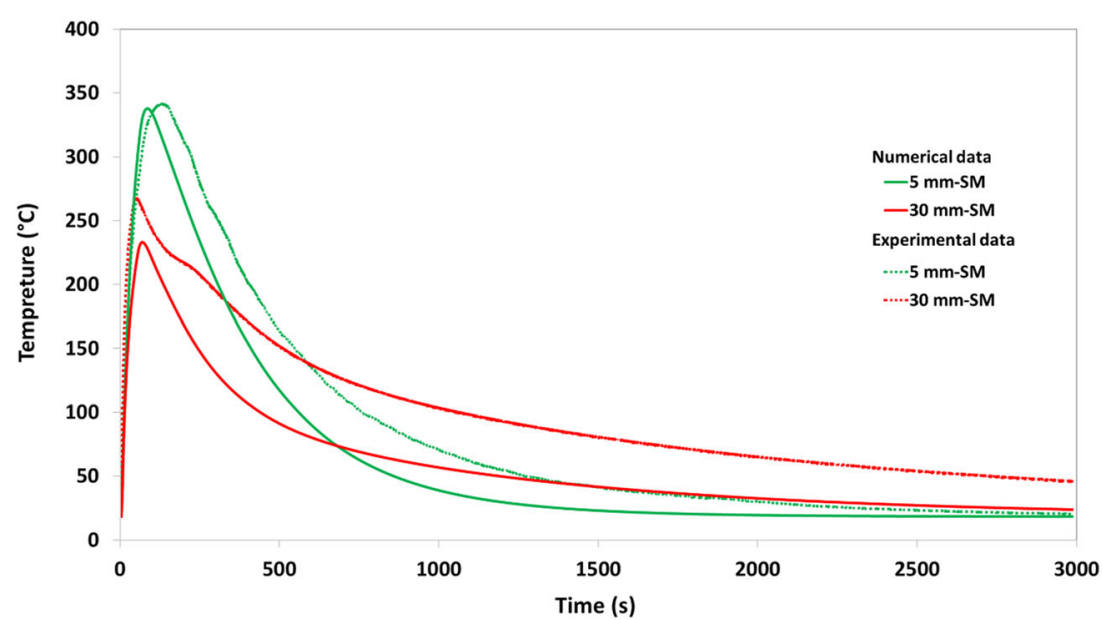


Fig. 10 Influence of the position of the thermocouples on the temperature evolution within the 30-mm SM

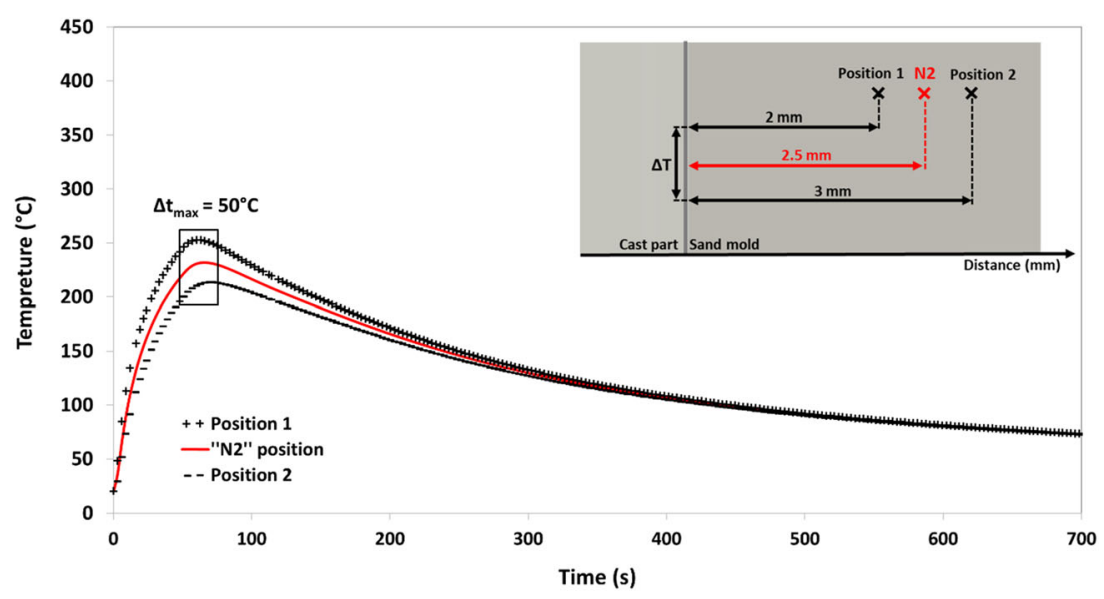

microstructure differences are expected since the solidification of the $30-\mathrm{mm}$-SM cast part was faster than 5 -mm-SM cast part, as shown in the previous section. This result is confirmed by the hardness measurements performed on both samples. The hardness average value increased from $58 \pm 1.8$ HV 5 to $64 \pm 1.2$ HV5, i.e., by about $10.3 \%$, when the 3DP sand mold thickness increased from 5 to $30 \mathrm{~mm}$. All the revealed microstructural differences confirm that the 3DP sand mold thickness affects significantly the microstructure of cast parts and consequently its mechanical properties.

It is important to have a thorough understanding of sand mold thickness impact on the solidification process of casting.
According to both numerical and experimental works in the eutectic AlSi13 alloy, increasing the 3DP sand thickness allows to accelerate the solidification of the casting. Thus, the interlamellar spacing decreases and a finer microstructure is obtained, which enhances the hardness of the casting and consequently, the mechanical properties are higher. Nevertheless, the inverse effect can be very useful in certain cases, in particular in the case of risers. Keeping the metal liquid within a riser during the cast-part solidification is a major objective in the casting process because it allows to produce a sound part (cf. without shrinkage porosity) [49]. For this purpose, exothermic risers are often used to delay the solidification of alloy
Fig. 11 Optical micrographs of samples obtained from as-cast AlSi13 alloy in a 5-mm SM and b 30-mm SM. a, d Zoom of the black-boxed areas in $\mathbf{a}$ and $\mathbf{b}$, respectively

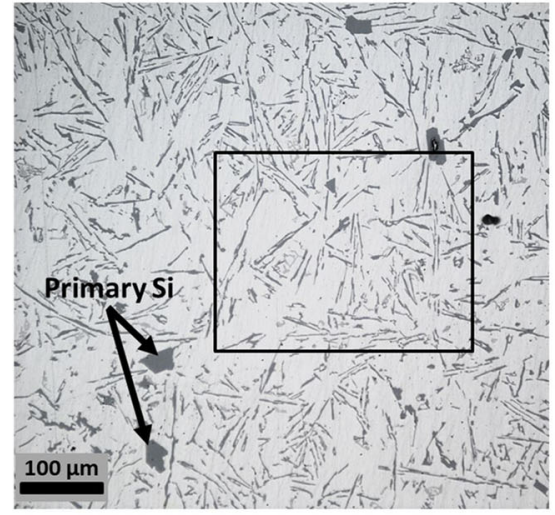

a

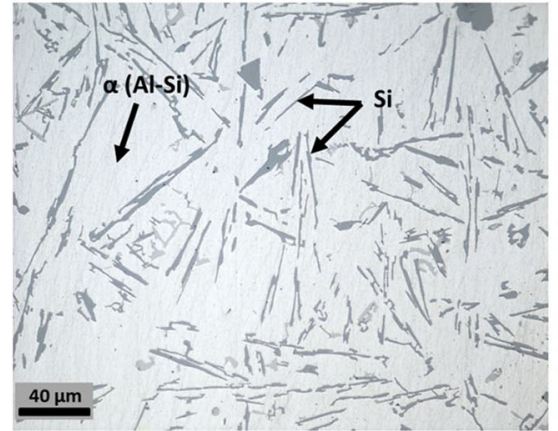

C

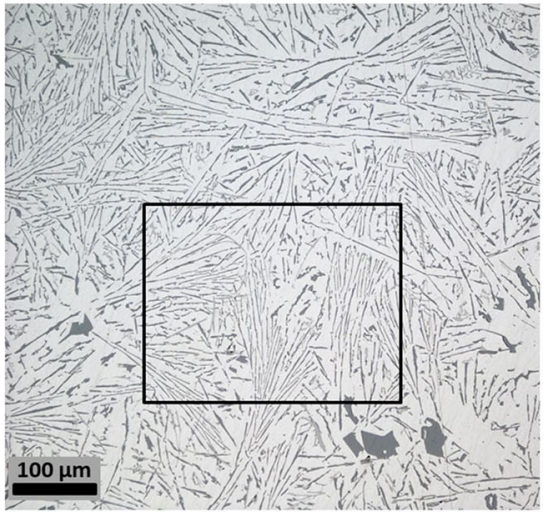

b

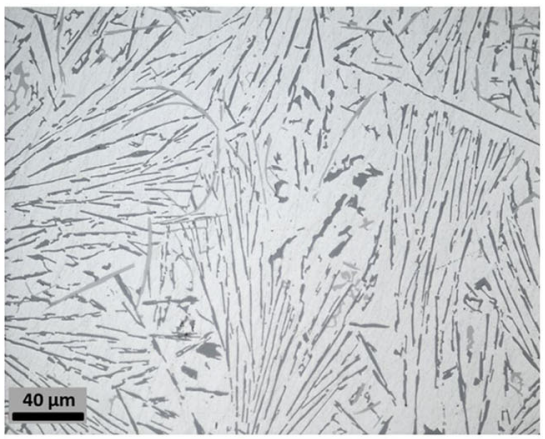


in the riser [50-53]. Instead of using relatively expensive solutions that are sometimes complicated to implement in the sand molds, reducing the sand thickness around the riser is an efficient way to make the solidification time longer by producing insulation effect. That is linked to the blockage mechanism, which takes place in the interface sand mold/air.

\section{Conclusion}

The present work contributed to a better understanding of 3DP sand thickness effects on the solidification process of AlSi13 casting. Numerical simulations and experiments were performed in the case of simple cylindrical cast part and molds. Both results were consistent and they highlighted the impact of sand thickness on the solidification of cylindrical cast parts. They showed that the solidification time could be reduced by increasing the sand mold thickness that affected significantly the microstructure and the mechanical properties of cast parts. The numerical results showed that the solidification was accelerated by more than $40 \%$ when the sand thickness of molds increased from 3 to $30 \mathrm{~mm}$. In the case of the studied part shape, a $15 \mathrm{~mm}$ of sand mold thickness allowed to obtain a good compromise between the solidification time and the quantity of printed sand - in other words - between the mechanical properties and the manufacturing cost. The experimental validation was performed on 5-mm SM and 30-mm SM. The study indicated that increasing the sand mold thickness from 5 to $30 \mathrm{~mm}$ allowed to accelerate the solidification by $17 \%$ and $18.6 \%$, respectively, in the numerical and experimental results. Hence, the interlamellar $(\alpha / \mathrm{Si})$ space decreased which enhance the strength of the as-cast AlSi13 parts. Thus, the hardness average value measured on the cast sample increased by $10.3 \%$.

This work was interested in studying the case of cylindrical cast parts and molds. The studied case was preliminary and simplified, while it is the first step to highlight the impact of the 3DP sand mold Thickness. In our coming work, we will experimentally characterize the heat transfer properties of the furan-bonded sand. The obtained data will be then introduced into the database of the Quikcast simulation software. This will allow to simulate the solidification of the casting in the mold with high accuracy and consequently to work on fairly complex cast parts and sand molds without having to go through experiments each time. We will also focus on making correlations between the printing parameters $\left(X_{\mathrm{r}}, R_{\mathrm{s}}\right)$, the sand thickness. These correlations could be very useful to master the casting properties and to obtain the desired ones according to the cast-part usage.

Acknowledgements The authors acknowledge the contribution of colleagues. Thanks are due to J. Bourgeois and J. Nègre of the Arts et Metiers ParisTech for their technical support.
Author contribution Mariem BEN SAADA carried out the numerical and experimental works. The manuscript was written by Mariem BEN SAADA in collaboration with Mohamed EL MANSORI. All authors discussed the results and commented on the manuscript and all the authors read and approved the final manuscript.

Availability of data and material The data supporting the conclusion of this article are included within the article. Any queries regarding these data may be directed to the corresponding author.

Code availability Not applicable.

\section{Declarations}

Ethical approval Not applicable.

Consent to participate All the authors agree to participate in this research study.

Consent to publish The authors both consent to have the data published.

Competing interests The authors declare no competing interests.

\section{References}

1. Budzik G (2007) Possibilities of utilizing 3DP technology for foundry mould making. Arch Foundry Eng 7:65-68 http:// journals.pan.pl/dlibra/journal/96939

2. Wang J, Sama SR, Manogharan G (2019) Re-thinking design methodology for castings: 3D sand-printing and topology optimization. Inter Metalcast 13:2-17. https://doi.org/10.1007/s40962-018-0229-0

3. Vaezi M, Chua CK (2011) Effects of layer thickness and binder saturation level parameters on 3D printing process. Int J Adv Manuf Technol 53:275-284. https://doi.org/10.1007/s00170-010-2821-1

4. Kafara M, Kemnitzer J, Westermann HH, Steinhilper R (2018) Influence of binder quantity on dimensional accuracy and resilience in 3D-printing. Procedia Manuf 21:638-646. https://doi.org/10. 1016/j.promfg.2018.02.166

5. Upadhyay M, Sivarupan T, El Mansori M (2017) 3D printing for rapid sand casting - a review. J Manuf Process 29:211-220. https:// doi.org/10.1016/j.jmapro.2017.07.017

6. Mitra S, Rodríguez de Castro A, El Mansori M (2018) The effect of ageing process on three-point bending strength and permeability of 3D printed sand molds. Int J Adv Manuf Technol 97:1241-1251. https://doi.org/10.1007/s00170-018-2024-8

7. Coniglio N, Sivarupan T, El Mansori M (2018) Investigation of process parameter effect on anisotropic properties of $3 \mathrm{D}$ printed sand molds. Int J Adv Manuf Technol 94:2175-2185. https://doi. org/10.1007/s00170-017-0861-5

8. Snelling D, Blount H, Forman C, Ramsburg K, Wentzel A, Williams C, Williams C, Druschitz A (2013) The effects of 3D printed molds on metal castings. In Proceedings of the Solid Freeform Fabrication Symposium 827-845.

9. Singamneni S, McKenna N, Diegel O, Singh D, Neitzert T, George JS, Choudhury AR, Yarlagadda P (2009) Rapid casting: a critical analysis of mould and casting characteristics. Aust J Mech Eng 7: 33-43. https://doi.org/10.1080/14484846.2009.11464576

10. Khandelwal H, Ravi B (2016) Effect of molding parameters on chemically bonded sand mold properties. J Manuf Process 22: 127-133. https://doi.org/10.1016/j.jmapro.2016.03.007 
11. Snelling D, Li Q, Meisel N, Williams CB, Romesh CB, Druschitz AP (2015) Lightweight metal cellular structures fabricated via 3D printing of sand cast molds. Adv Eng Mater 17:923-932. https:// doi.org/10.1002/adem.201400524

12. Martof A, Gullapalli R, Kelly J, Rea A, Lamoncha B, Walker JM, Conner B, MacDonald E (2018) Economies of complexity of 3D printed sand molds for casting. In Proceedings of the $29^{\text {th }}$ Annual International Solid Freeform Fabrication Symposium (pp. 117-134)

13. Sama SR, Jiayi W, Manogharan G (2018) Non-conventional mold design for metal casting using 3D sand-printing. J Manuf Process 34:765-775. https://doi.org/10.1016/j.jmapro.2018.03.049

14. Sama SR, Badamo T, Lynch P, Manogharan GP (2019) Novel sprue designs in metal casting via 3D sand-printing. Addit Manuf 25:563-578. https://doi.org/10.1016/j.addma.2018.12.009

15. Shangguan H, Kang J, Deng C, Hu Y, Huang T (2017) 3D-printed shell-truss sand mold for aluminum castings. J Mater Process Technol 250:247-253. https://doi.org/10.1016/j.jmatprotec.2017. 05.010

16. Shangguan H, Kang J, Yi J, Zhang X, Wang X, Wang H, Huang T (2018) The design of 3D-printed lattice-reinforced thicknessvarying shell molds for castings. Materials 4:535. https://doi.org/ 10.3390/ma1 1040535

17. Kang J, Shangguan H, Deng C, Hu Y, Yi J, Wang X, Zhang W, Huang $T$ (2018) Additive manufacturing-driven mold design for castings. Addit Manuf 22:472-478. https://doi.org/10.1016/j. addma.2018.04.037

18. Waurzyniak P (2003) Rapid metal-rapid manufacturing and rapid tooling for metal parts gain support. Manuf Ing 131:49-57

19. Singh R, Verma M (2008) Investigations for deducing wall thickness of aluminium shell casting using three dimensional printing. $\mathrm{J}$ Achiev Mater Manuf Eng 31:565-569

20. Singh R (2009) Three dimensional printing for casting applications: a state of art review and future perspectives. Adv Mater Res 83-86: 342-349. https://doi.org/10.4028/www.scientific.net/AMR.83-86. 342

21. Gill SS, Kaplas M (2011) Efficacy of powder-based three-dimensional printing (3DP) technologies for rapid casting of light alloys. Int J Adv Manuf Technol 52:53-64. https://doi.org/10.1007/ s00170-010-2716-1

22. Chhabra M, Singh R (2015) Mathematical modeling of surface roughness of castings produced using Zcast direct metal casting. J Inst Eng India Ser C 96:145-155. https://doi.org/10.1007/s40032014-0139-8

23. Akhil KT, Sanjivi A, Sellamuthu R (2014) The effect of section size on cooling rate, microstructure and mechanical properties of A356 aluminium alloy in casting. Procedia Mater Sci 5:362-368. https:// doi.org/10.1016/j.mspro.2014.07.278

24. Dong QZ, Choi YS, Hong JH, Hwang HY (2012) Prediction of mechanical properties of $\mathrm{Al}$ alloys with change of cooling rate. China Foundry 9:381-386

25. Tawele PK, Raut LP (2015) Warpage in casting: a Review. International Journal of Advanced Research in Engineering, Science and Technology 2:1-7. https://doi.org/10.6084/m9. figshare.4487633.v1

26. Vega Valeri A (2015) Study for the numerical resolution of conservation equations of mass, momentum and energy to be applied on vortexinduced vibrations of cylindrical structures. Polytechnic University of Catalonia, Dissertation

27. Sang B, Kang X, Li D (2010) A novel technique for reducing macrosegregation in heavy steel ingots. J Mater Process Technol 210:703-711. https://doi.org/10.1016/j.jmatprotec.2009.12.010

28. Sun HC, Chao LS (2009) An investigation into the effective heat transfer coefficient in the casting of aluminium in a green-sand mold. Mater Trans 50:1396-1403. https://doi.org/10.2320/ matertrans.MRA2008364

29. Afazov SM, Becker AA, Hyde TH (2011) FE prediction of residual stresses of investment casting in a bottom core vane under equiaxed cooling. J Manuf Process 13:30-40. https://doi.org/10.1016/j. jmapro.2010.10.001

30. Lee SJ, Sachs E, Cima M (1995) Layer position accurancy in powder based rapid prototyping. Rapid Prototyp J 1:24-37. https://doi. org/10.1108/13552549510104447

31. Mitra S, Rodríguez de Castro A, El Mansori M (2019) On the rapid manufacturing process of functional 3D printed sand molds. J Manuf Process 42:202-212. https://doi.org/10.1016/j.jmapro. 2019.04.034

32. Mitra S, El Mansori M, Rodríguez de Castro A, Costin M (2020) Study of the evolution of transport properties induced by additive processing sand mold using X-ray computed tomography. J Mater Process Technol 277:116495. https://doi.org/10.1016/j.jmatprotec. 2019.116495

33. Sivarupan T, El Mansori M, Daly K, Mavrogordato MN, Pierron F (2019) Characterisation of 3D printed sand moulds using microfocus X-ray computed tomography. Rapid Prototyp J 25:404 416. https://doi.org/10.1108/RPJ-04-2018-0091

34. Sivarupan T, El Mansori M, Coniglio N, Dargusch M (2020) Effect of process parameters on flexure strength and gas permeability of 3D printed sand molds. J Manuf Process 54:420-437. https://doi. org/10.1016/j.jmapro.2020.02.043

35. Koltygin AV, Bazhenov VE (2012) Development of a substitute for $\mathrm{Z}$ cast molding sand used on installations of 3D printing for obtaining aluminum, magnesium, and iron casting. Russian Journal of Non-Ferrous Metals 53:38-41. https://doi.org/10.3103/ S1067821212010129

36. Miyanaji H, Momenzadeh N, Yang L (2018) Effect of printing speed on quality of printed parts in binder jetting process. Addit Manuf 20:1-10. https://doi.org/10.1016/j.addma.2017.12.008

37. Zamani M (2017) Al-Si Cast alloys-microstructure and mechanical properties at ambient and elevated temperatures. Jönköping University, School of Engineering, Dissertation

38. Kaufman JG, Rooy EL (2004) Aluminum alloy castings: properties, processes, and applications. Asm International.

39. Zolotorevsky VS, Belov NA, Glazoff MV (2007) Industrial Casting Aluminum Alloys. In: Casting aluminum alloys. Elsevier, Amsterdam

40. Vander Voort GF, Asensio-Lozano J (2009) The Al-Si Phase diagram. Microsc Microanal 15:60-61. https://doi.org/10.1017/ S1431927609092642

41. Campbell J (2015) Complete casting handbook: metal casting processes, metallurgy, techniques and design. ButterworthHeinemann, Oxford

42. Pang S, Wu GH, Liu WC, Zhang L, Zhang Y, Conrad H, Ding WJ (2015) Influence of pouring temperature on solidification behavior, microstructure and mechanical properties of sand-cast $\mathrm{Mg}-10 \mathrm{Gd}$ $-3 \mathrm{Y}-0.4 \mathrm{Zr}$ alloy. Trans Nonferrous Metals Soc China 25:363-374. https://doi.org/10.1016/S1003-6326(15)63612-3

43. Gündüz M, Kaya H, Çadırlı E, Özmen A (2004) Interflake spacings and undercoolings in Al-Si irregular eutectic alloy. Mater Sci Eng A369:215-229. https://doi.org/10.1016/j.msea.2003.11.020

44. Meng GH, Lin X, Huang WD (2008) Interlamellar spacing and average interface undercooling of irregular eutectic in steady-state growth. Trans Nonferrous Metals Soc China 18:405-409. https:// doi.org/10.1016/S1003-6326(08)60071-0

45. Jiang W, Fan Z, Chen X, Wang B, Wu H (2014) Combined effects of mechanical vibration and wall thickness on microstructure and mechanical properties of A356 aluminum alloy produced by 
expendable pattern shell casting. Mater Sci Eng A 619:228-237. https://doi.org/10.1016/j.msea.2014.09.102

46. Ghedjati K, Fleury E, Guellati O, Samih Y (2018) Elaboration of AlSi13 casting alloys modified using directional solidification processing. "Synthèse: Revue des Sciences et de la Technologie" 37: $14-24$.

47. Jiang W, Fan Z, Liu D, Liao D, Dong X, Zong X (2013) Correlation of microstructure with mechanical properties and fracture behavior of A356-T6 aluminum alloy fabricated by expendable pattern shell casting with vacuum and low-pressure, gravity casting and lost foam casting. Mater Sci Eng A 560:396-403. https://doi.org/10. 1016/j.msea.2012.09.084

48. Jiang W, Chen X, Wang B, Fan Z, Wu H (2016) Effects of vibration frequency on microstructure, mechanical properties and fracture behavior of A356 aluminum alloy obtained by expendable pattern shell casting. Int J Adv Manuf Technol 83:167-175. https://doi.org/ 10.1007/s00170-015-7586-0

49. Campbell J (2004) Castings practice, the 10 rules of casting. Elsevier Butterworth-Heinemann, Oxford
50. Brown JR (2000) Foseco ferrous foundryman's Handbook. Butterworth-Heinemann, United Kingdom

51. Yücel O, Turan A, Candeğer KC (2018) Effects of changing sizeweight parameters on the temperature dependent exothermic riser sleeve properties. Eurasian Chem-Technol J 20:17-21. https://doi. org/10.18321/ectj704

52. Ji KF, Shen MG, Li RT, Zhu XL, Zhang ZS (2019) Simulation study on influence of exothermic riser on ingot solidification. Metalurgija 58:33-35

53. Idamayanti D, Purwadi W, Bandanadjaja B, Triadji R (2020) Risk husk waste an exothermic material for a riser sleeve for steel casting. Int J Technol 11:71-80. https://doi.org/10.14716/ijtech.v11i1. 2544

Publisher's note Springer Nature remains neutral with regard to jurisdictional claims in published maps and institutional affiliations. 